\title{
Effective Factors of Utilization of Inpatient, Outpatient, Diagnostic, and Pharmaceutical Health Services: A Systematic Review
}

\author{
Solmaz Azimzadeh ${ }^{1}$, Jafar Sadegh Tabrizi², Shirin Nosratnejad ${ }^{3}$, Mostafa Farahbakhsh², Saber Azami Aghdash ${ }^{4}$, \\ Hossein Mashhadi Abdolahi ${ }^{2 \bowtie}$

\begin{abstract}
${ }^{1}$ Iranian Center of Excellence in Health Management and Department of Health Service Management, School of Management and Medical Informatics, Tabriz University of Medical Sciences, Tabriz, Iran

${ }^{2}$ Tabriz Health Services Management Research Center, Health Management and Safety Promotion Research Institute, Tabriz University of Medical Sciences, Tabriz, Iran

${ }^{3}$ Department of Health Services Management, Faculty of Management and Medical Informatic, Tabriz University of Medical Sciences, Tabriz, Iran

${ }^{4}$ Road Traffic Injury Research Center, Tabriz University of Medical Sciences, Tabriz, Iran
\end{abstract}

\begin{abstract}
Utilization is one of the dimensions of equity in health systems. Identifying the factors affecting utilization of health services can be helpful for interventional purposes. This study systematically reviewed the factors affecting the utilization of inpatient, outpatient, diagnostic, and pharmaceutical services. This systematic review was conducted between 2016 and 2017. The search was performed using keywords based on MeSH in valid databases such as Scopus, Embase, ProQuest, ScienceDirect, PubMed, and Web of Science in the fields of title, abstract, and keyword. Related papers published from 2000 to 2017 were searched. First, the retrieved studies were screened and checked for quality; then, the useful data were extracted and analyzed. Out of the 1178 retrieved publications, 20 studies were included in the final analysis. The identified factors were categorized into 5 areas, including demographic (4 items), socioeconomic (13 items), health services-related (13 items), health status-related ( 7 items), and health insurance-related factors ( 2 items), and reported. The findings of this study can be a useful source and a comprehensive body of evidence on the utilization of health services. The results can be used by the policy makers and managers in designing interventions for changing the utilization patterns of health services. [GMJ.2019;8:e1236] DOI:10.22086/gmj.v8i0.1236
\end{abstract}

Keywords: Utilization; Health Services; Inpatient; Outpatient; Diagnostics; Pharmaceuticals

\section{Introduction}

$\mathrm{H}$ ealth is a matter of importance in today's modern societies in such a way that we might conclude that improvements of health indicators lead to human and social development and then elevate the development

\section{GMJ}

Copyright $\odot$ 2019, Galen Medical Journal. This is an open-access article distributed under the terms of the Creative Commons Attribution 4.0 Internationa License (http://creativecommons.org/licenses/by/4.0/) Email:info@gmj.ir status of the country [1]. Management of the health system requires evidence-informed decisions and some deep knowledge on the utilization of health services [2]. Today, health-related views have expanded and nonmedical determinants of health have gained special attention. These determinants,

\footnotetext{
Correspondence to:

Hossein Mashhadi Abdolahi, Building No. 3 Tabriz University of Medical Sciences, Tabriz Health

Services Management Research Center Telephone Number: +989144000823

Email Address: hm_abdolahi@yahoo.com
} 
individually or by affecting others, seriously influence the health of people. Although health care results in the prevention of diseases, improvement of health, and treatment of illnesses, the socioeconomic status and the social determinants of health are highly influencing the health, illness, and need for medical care [3]. Reducing the inequalities in gender, races, and age groups is one of the main goals of the health policy makers [4]. Moreover, one dimension of equity is the utilization of health services [5]. The equitable access of all members of the society to health services leads to the improvement of health status in the whole population, and it prepares the requirements of growth and development [6]. As the effective factors on the utilization of health services are among the key determinants of community health, many researchers and health policy makers are interested in them [7]. Evidence shows that socioeconomic differences, by influencing the utilization rate of health services, lead to inequality in access to health care and thus an increase in the burden of diseases. Access is the first step for health services utilization and plays a main role in it [8]. Studies have shown that the utilization of health services is affected by many factors such as demographic factors, socioeconomic and cultural factors, health needs of the individuals, and access to the health facilities. On the other hand, poor socioeconomic conditions and lifestyle factors increase the burden of diseases, and resultantly, the need for health services [911]. Various models have been developed for understanding the pattern of health services utilization up to now. The model proposed by Andersen (2005) describes the health care utilization as a model of behavior. It considers the utilization of health services as a dependent factor of ability to use, barriers to use, and the need for the services. Furthermore, some people tend to use more health services than others, which can be predicted by some characteristics. Individuals with such characteristics of demographic factors, social factors, incentives, and beliefs are more likely to use the health services. In addition to the predictive factors of utilization, some other factors such as income, health insurance, availability, and access are necessary, without which the utilization would not occur [12]. The research on utilization of health services enables us to identify its facilitators and barriers and also to investigate the appropriateness of the volume and quality of the services [13]. The health services include a wide range of services, each of which is influenced by a number of other factors. Therefore, this study was conducted with the aim of identifying the effective factors on the utilization of inpatient, outpatient, diagnostic, and pharmaceutical health services.

\section{Materials and Methods}

This systematic review was conducted between 2016 and 2017, and it was based on the Preferred Reporting Items for Systematic Reviews and Meta-Analyses guidelines.

\section{Data Sources}

The existing scientific papers in English and Persian published between January 2000 and September 2017 were retrieved through searching English databases such as Scopus, Embase, ProQuest, ScienceDirect, PubMed, and Web of Science and also Persian databases such as SID and Magiran. Furthermore, the Google Scholar search engine was used for additional search of the related literature. The search keywords were "healthcare utilization," "healthcare utilization," "health service utilization" and "factors affect*," "factors influenc*," "affect* factors," "influenc* factors," "clinic/outpatient," "hospitalization/inpatient," "drug/medicine," and "paraclinic/diagnos*." The references of the related papers were also checked by hand for additional studies.

\section{Inclusion and Exclusion Criteria}

There were 2 main inclusion criteria: (1) papers published between January 2000 and September 2017 and (2) papers investigating the effective factors of the utilization of inpatient, outpatient, diagnostics, and pharmaceutical health services. Meanwhile, there were 4 major exclusion criteria: (1) studies conducted before January 2000, (2) studies without a published full text, (3) studies published in languages other than Persian and English, and (4) papers studying 
specific populations such as immigrants or a specific disease such as AIDS or any other specific diseases.

\section{Screening}

The retrieved corpus was pooled in EndNote X7 software produced by Thomson Reuters Company, and the duplicates were identified and removed. Then, the irrelevant papers were identified and excluded first by title screening and then by abstract screening. Finally, the full texts of the remaining papers were reviewed for eligibility according to the inclusion and exclusion criteria.

\section{Quality Appraisal}

To assess the quality of the included papers, the Strengthening the Reporting of Observational Studies in Epidemiology checklist was used [14]. This checklist includes 22 items. The assessment was performed by 2 independent researchers. Each item had 1 score, and if the item had not passed, it got 0 score. In case of disagreement between the assessors about the score of the paper on a specific item, the case was discussed and resolved. Finally, those papers that gained $50 \%$ and more of the total possible score were included in the final analysis.

\section{Data Extraction}

The required data were determined based on the study purpose and then extracted by one researcher and rechecked by another. The collected data were entered into an MS Excel spreadsheet in a table. The extraction table included information such as names of the authors, publication year, country, study type, sample size, data collection method, related findings, and the result of the quality assessment of the paper. To develop the table, the data related to 5 studies were extracted as pilot, and then the table was reviewed and revised.

\section{Data Analysis}

Content analysis, which is a widely used qualitative research technique, was used in this study to analyze the extracted data. First, the influencing factors were identified from the content of the included papers. Then, the findings were coded and categorized as similar and related factors to be in the same category. The categories were named to describe the contents. Finally, the frequency of the codes was counted, and the results were presented in tables.

\section{Results}

Out of the total 1178 retrieved papers, 350 were duplicates that were excluded from the study. The remaining 828 records were first screened by title and then by abstract. Finally, after finishing the screening phase, 20 studies were included in the analysis. Figure- 1 shows the search and selection process of the studies. The data were extracted from the final 20 included studies, and the affecting factors on the utilization of services were identified. The factors were divided into 2 groups of positive effect and negative effect. Table-1 shows the characteristics of the included studies and the main findings of each study as the factors affecting the utilization of health services. Out of the total 20 included studies, 12 were conducted in Asia and 8 were crosssectional. The data used in 6 studies were secondary data. The health services were arranged in 4 groups of inpatient services, outpatient services, diagnostic procedures, and pharmaceutical services. Four studies had investigated the pharmaceutical services, 6 studies the diagnostic services, 8 studies the inpatient services, and 10 studies the outpatient services. A total of 45 factors were identified as having a positive effect on the utilization of health services and 8 factors as having a negative effect. The identified factors were classified into the following 5 categories:

1. Demographic factors $(n=4)$, which included age, sex, marital status, and family size.

2. Socioeconomic factors $(n=12)$, which included education, income level, employment, race, household expenditures, urban area, living place, using social media, health literacy, regular study, rented house, and the characteristics of family members.

3. Health service-related factors $(n=13)$, which included physician visit, use of preventive care, medical technology growth, medical regulations, 


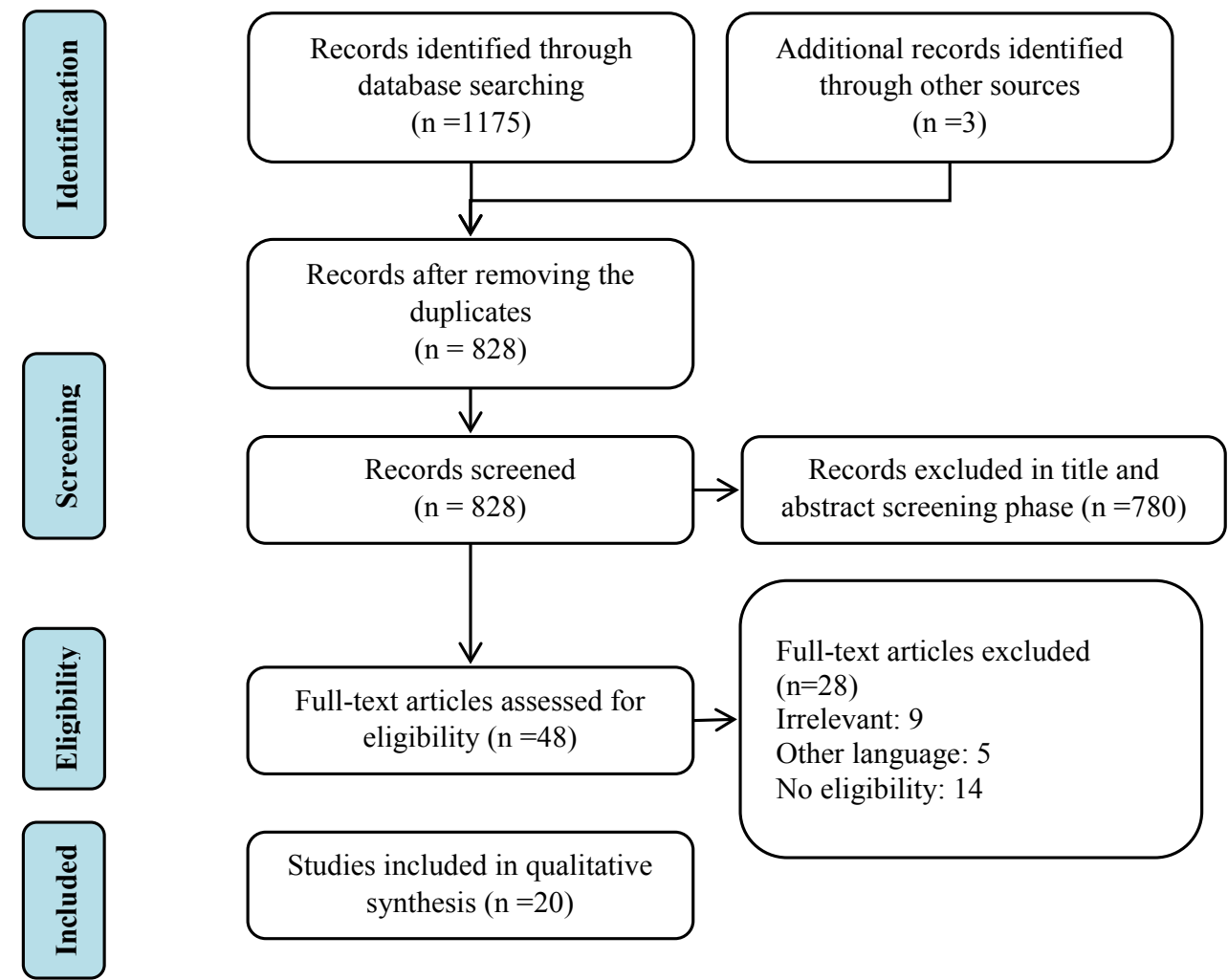

Figure 1. Search and selection process of the studies

4. hospitalization, length of hospital stay, grade of hospital, use of traditional medicine, physician's qualifications, provider experience, access to health facilities, distance to health facilities, and regular care.

5. Factors related to the health status of individuals $(\mathrm{n}=8)$, which included chronic diseases, poor health condition, stressful life event, smoking, alcohol consumption, regular physical activity, days with disability, and inactivity.

6. Health insurance-related factors $(n=2)$, which included insurance status and the insurance type.

Table-2 shows the summary of the identified effective factors on the utilization of health services.

\section{Discussion}

This study reviewed the effective factors on the utilization of health services worldwide in the following 4 categories: pharmaceutical services, diagnostic procedures, inpatient services, and outpatient services. The identified factors were organized into 5 groups: demographic factors (4 factors), socioeconomic factors (13 factors), factors related to health services (13 factors), factors related to health status of the individuals (7 factors), and factors related to health insurance ( 2 factors). The determinants of health services utilization were vast and included a variety of factors that were related to the people and health care providers. The factors had been studied differently in various studies. Some studies had categorized the factors by the type of services, whereas other studies had categorized them by the type of clients. In this study, we tried to summarize the determinant factors of health services utilization in a simple and understandable way. Numerous studies have assessed the utilization of health services in different countries and in various populations to depict the demand for the services. Thus, the health system would be able to provide the services in a responsible manner to meet the health needs of the population. Findings of the studies on individual, social, and economic determinants of health services utilization 


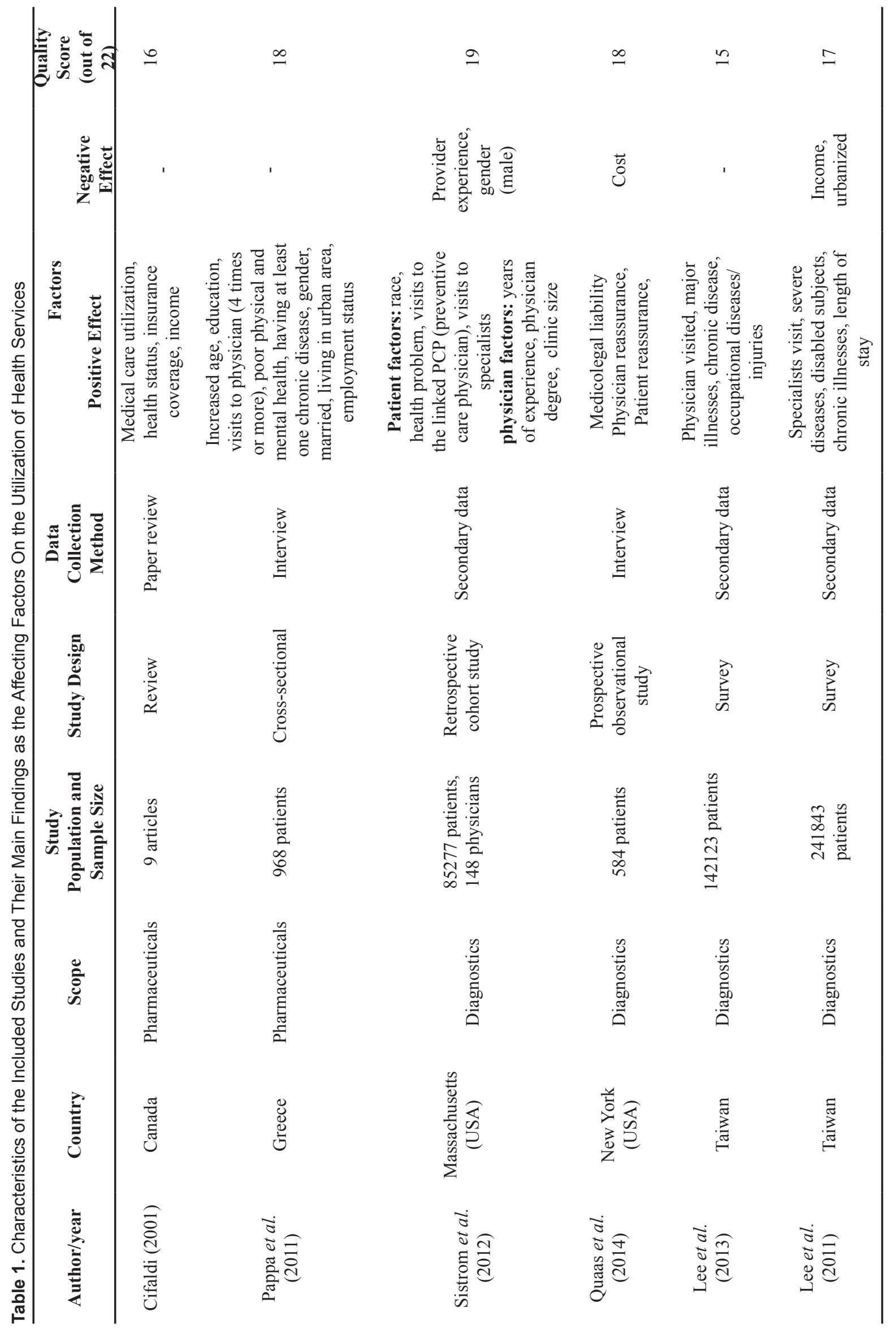


N

ำ

a

$\infty$

2

Ә

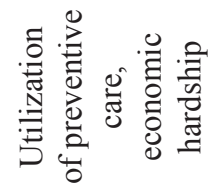

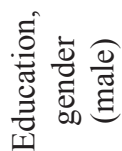

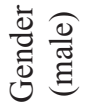

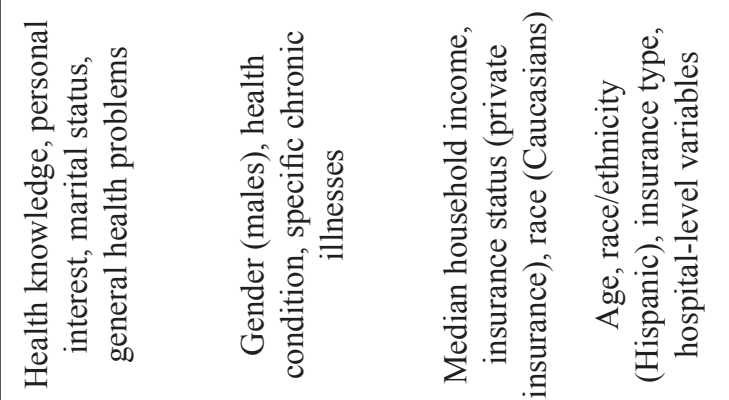
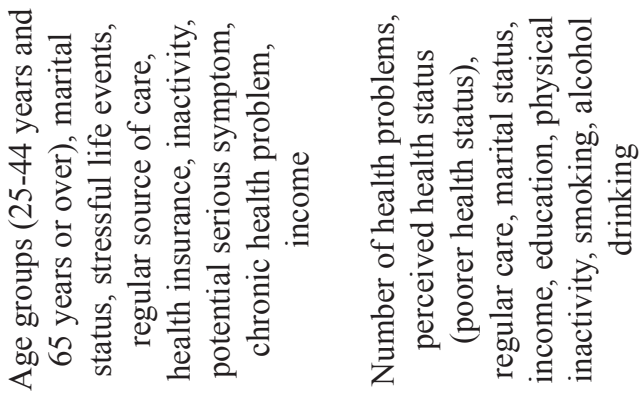

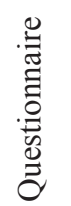

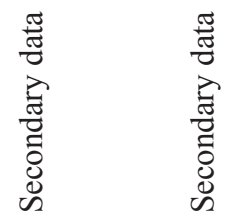

.

.

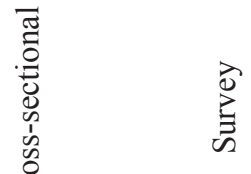

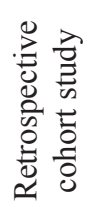

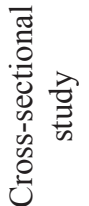

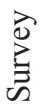

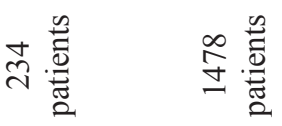

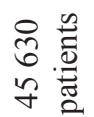

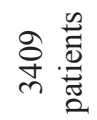

은.

ํ.

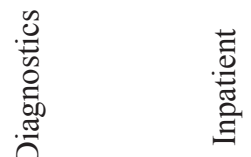

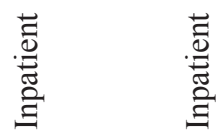

泀
营
0

.

岕

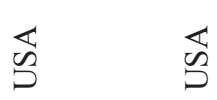

武

节

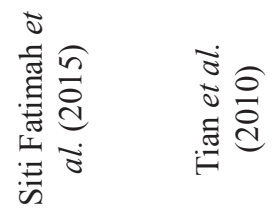

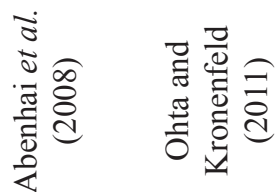

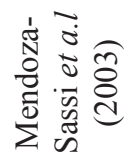

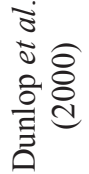


$\stackrel{\infty}{\infty}$

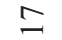

9

ำ

毫量

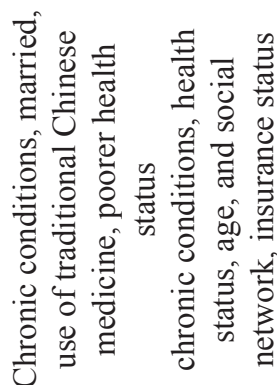

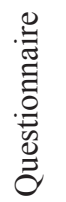

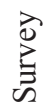

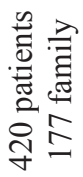

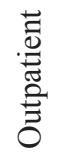

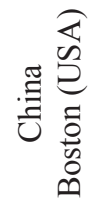

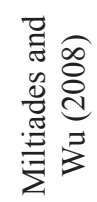

.

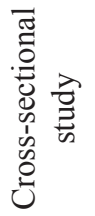

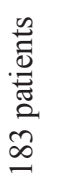

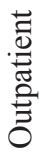

$\frac{\sqrt[\pi]{5}}{\frac{0}{5}}$

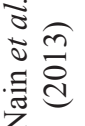

:

$\overrightarrow{0}$
0
0
0
0
1
0
0
0
0

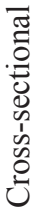

$\frac{y}{0}$
0
0
0
0
0
$\frac{1}{8}$
8
0

0
0
0
0
0
0
0
0
0

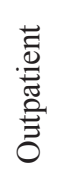

节

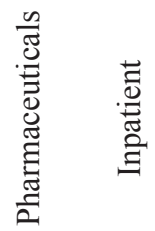

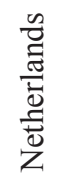

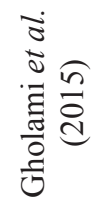




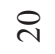
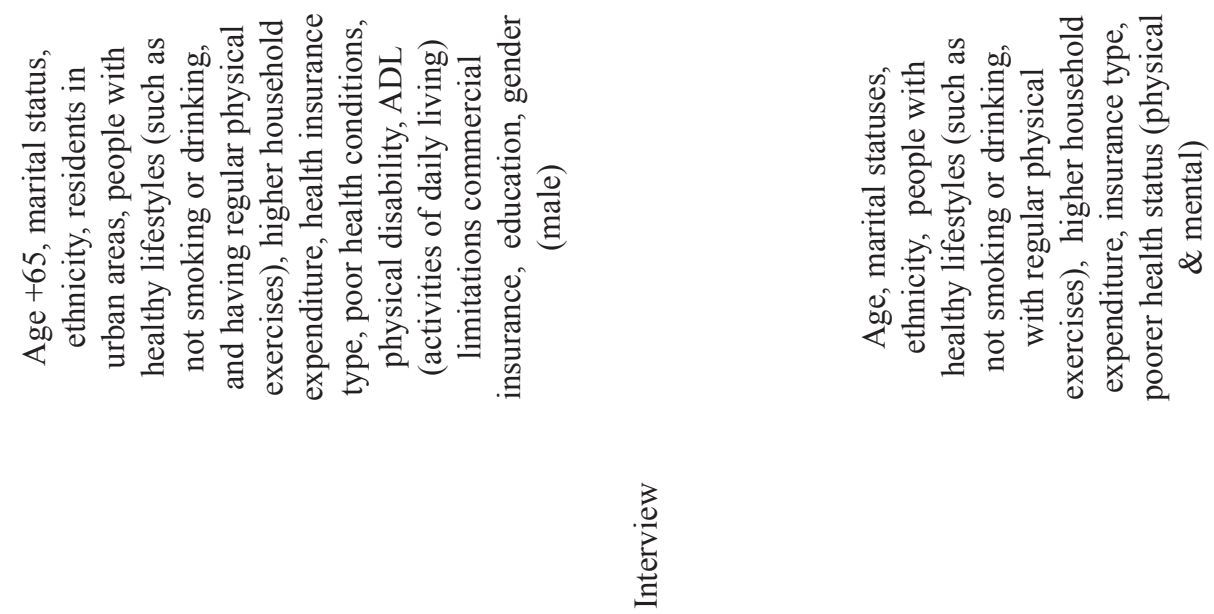

蒠
总
总
点

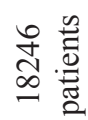

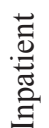

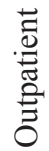

苞

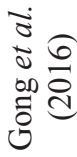



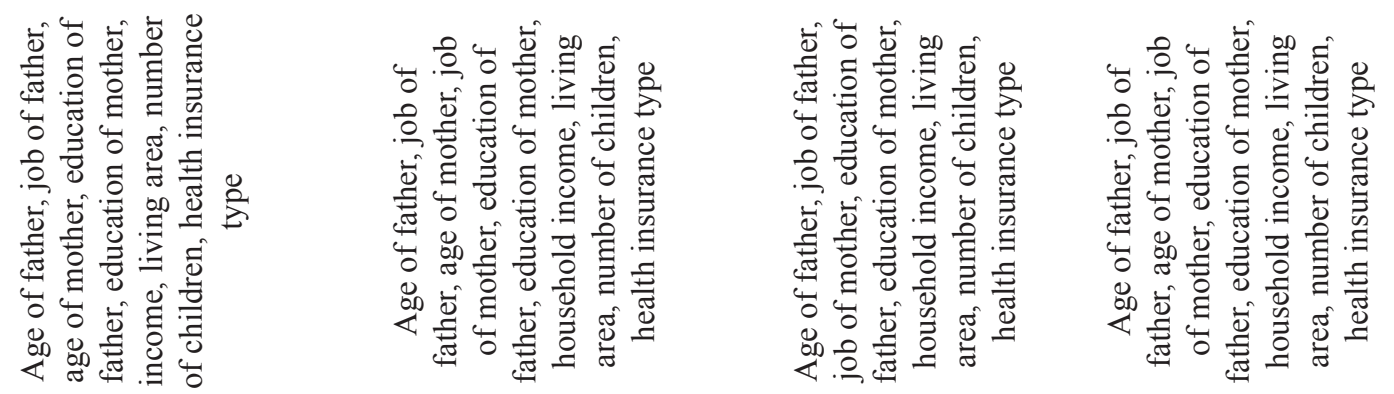

:

$\bar{\Xi}$
0
0
0
0
1
0
0
0
0

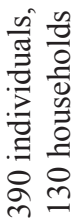

苞

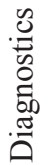

苞

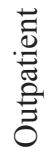

톨

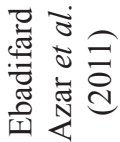




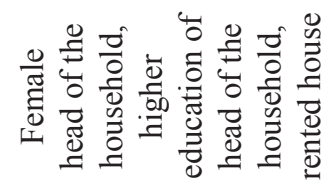

$\underline{2}$

$\because$

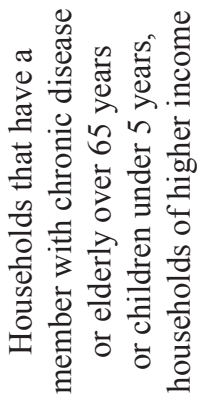

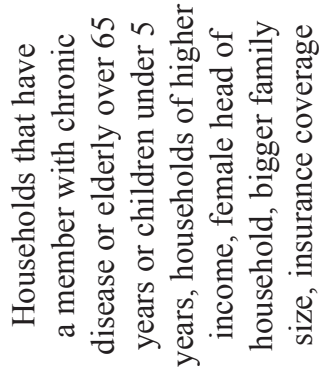

离

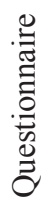
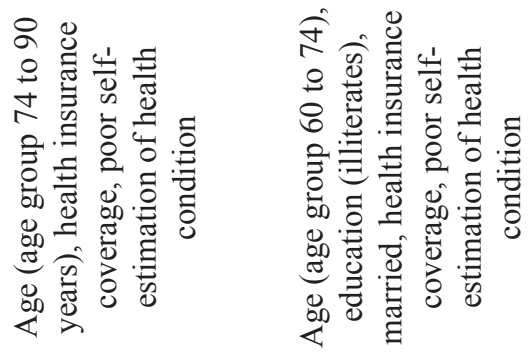

苞

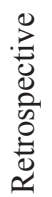

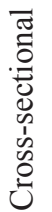

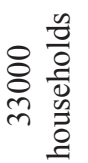

$\frac{n}{3}$
$\frac{\pi}{3}$
0
0
8
8

节

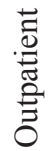

䔍
吾

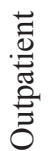

ฐี

ฐี

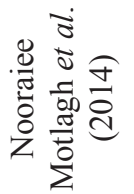

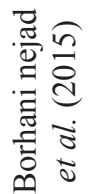


Table 2. Factors Affecting the Utilization of Health Services

\begin{tabular}{|c|c|c|c|c|c|}
\hline \multirow[b]{2}{*}{$\begin{array}{c}\text { Health } \\
\text { Services }\end{array}$} & \multicolumn{5}{|c|}{ Categories } \\
\hline & $\begin{array}{c}\text { Demographic } \\
\text { Factors }\end{array}$ & $\begin{array}{c}\text { Socioeconomic } \\
\text { Factors }\end{array}$ & $\begin{array}{c}\text { Factors } \\
\text { Related to } \\
\text { Health Status }\end{array}$ & $\begin{array}{l}\text { Health } \\
\text { Services- } \\
\text { Related } \\
\text { Factors }\end{array}$ & $\begin{array}{c}\text { Health } \\
\text { Insurance- } \\
\text { Related factors }\end{array}$ \\
\hline Pharmaceuticals & $\begin{array}{l}\text { Age, sex, } \\
\text { marital status, } \\
\text { household } \\
\text { size }\end{array}$ & $\begin{array}{c}\text { Education, } \\
\text { income, } \\
\text { employment, } \\
\text { urban area, } \\
\text { characteristics } \\
\text { of household } \\
\text { members }\end{array}$ & $\begin{array}{l}\text { Poor health } \\
\text { condition, } \\
\text { chronic } \\
\text { diseases }\end{array}$ & $\begin{array}{l}\text { Physician visit, } \\
\text { hospitalization }\end{array}$ & $\begin{array}{l}\text { Having health } \\
\text { insurance } \\
\text { coverage, having } \\
\text { private health } \\
\text { insurance }\end{array}$ \\
\hline Diagnostics & $\begin{array}{c}\text { Age, sex, } \\
\text { marital status }\end{array}$ & $\begin{array}{c}\text { Education, } \\
\text { income, } \\
\text { employment, } \\
\text { race, } \\
\text { household } \\
\text { expenditure, } \\
\text { urban area, } \\
\text { health literacy, } \\
\text { characteristics } \\
\text { of household } \\
\text { members }\end{array}$ & $\begin{array}{l}\text { Health } \\
\text { status of the } \\
\text { individual, } \\
\text { having chronic } \\
\text { disease }\end{array}$ & $\begin{array}{l}\text { Physician visit, } \\
\text { hospitalization, } \\
\text { hospital } \\
\text { length of stay, } \\
\text { academic } \\
\text { degree of } \\
\text { physician, } \\
\text { experience of } \\
\text { the provider, } \\
\text { access to } \\
\text { providers, } \\
\text { regulations }\end{array}$ & - \\
\hline Inpatient & $\begin{array}{c}\text { Age, sex, } \\
\text { marital status }\end{array}$ & $\begin{array}{c}\text { Education, } \\
\text { income, } \\
\text { employment, } \\
\text { race, } \\
\text { household } \\
\text { expenditure, } \\
\text { urban area, } \\
\text { rented house, } \\
\text { characteristics } \\
\text { of household } \\
\text { members }\end{array}$ & $\begin{array}{l}\text { Health } \\
\text { status of the } \\
\text { individual, } \\
\text { chronic } \\
\text { disease, } \\
\text { smoking, } \\
\text { alcohol, } \\
\text { regular } \\
\text { physical } \\
\text { activity }\end{array}$ & $\begin{array}{c}\text { Using } \\
\text { preventive } \\
\text { care, medical } \\
\text { technology } \\
\text { growth, hospital } \\
\text { grade }\end{array}$ & $\begin{array}{c}\text { Insurance } \\
\text { coverage, private } \\
\text { insurance }\end{array}$ \\
\hline Outpatient & $\begin{array}{l}\text { Age, sex, } \\
\text { marital status, } \\
\text { household } \\
\text { size }\end{array}$ & $\begin{array}{l}\text { Education, } \\
\text { income, } \\
\text { employment, } \\
\text { household } \\
\text { expenditure, } \\
\text { urban area, } \\
\text { rented house, } \\
\text { characteristics } \\
\text { of household } \\
\text { members }\end{array}$ & $\begin{array}{l}\text { Health } \\
\text { status of the } \\
\text { individual, } \\
\text { chronic } \\
\text { disease, } \\
\text { smoking, } \\
\text { alcohol, } \\
\text { regular } \\
\text { physical } \\
\text { activity, } \\
\text { stressful life } \\
\text { events }\end{array}$ & $\begin{array}{l}\text { Use of } \\
\text { traditional } \\
\text { medicine, } \\
\text { regular care, } \\
\text { distance to } \\
\text { clinic }\end{array}$ & $\begin{array}{c}\text { Insurance } \\
\text { coverage, private } \\
\text { insurance }\end{array}$ \\
\hline
\end{tabular}


indicate the needs of the societies for the health services. These findings can be used by the health system policy makers at the regional and national levels. For instance, studies that performed in China and Britain by the survey data found that similar socioeconomic groups have a similar utilization rate of the health services. Hence, based on these findings, they were looking for approaches to decrease the inequalities between the socioeconomic groups [15]. The results of the study showed that the demographic and socioeconomic factors were investigated more than other factors and were reported by more studies to have an effect on utilization of health services, in a way such that the demographic factors had been investigated in 15 studies and the socioeconomic factors in 16 studies out of the 20 included studies. Yet, some factors that correlate with health service utilization in a particular population on a particular group of health services may show no correlation in another population or another group of services. Even the effect of the factor might differ in different situations, for example, a particular factor may have a positive effect on the utilization of some services and simultaneously a negative effect on other services or in other regions or populations. Examples of this statement are discussed below. To conclude, the determinant factors of health services utilization are, to some extent, region-specific, and it is difficult to generalize them to all populations. In spite of this, findings of this review provided a basic understanding of the effective factors on the utilization of health services around the world. They can also be used as a list of potential factors for future studies. Some studies have mentioned education as a positive influencing factor on the utilization of health services $[3,12$, $16,17]$. This means that more the education level of the individual, more the use of health services. However, 2 studies reported that by increasing the education level, the utilization rate of health services decreases [11, 18]. This might be justified by the assumption that people with more education have a better health status and they need health services less than others. A similar conflict exists about sex. Pappa et al. (2011) reported that women use more pharmaceuticals than men [18].
Sistrom et al. (2012) reported that women use more diagnostic services than men [19]. Tian et al. (2010) and Borhaninejad et al. (2015) reported that men use more inpatient services than women [20], whereas the study by Gong et al. (2016) found women using more inpatient services than men [21]. Such differences might be justified by cultural, social, and genetic differences of the studied populations. Moreover, Mendoza-Sassi (2003) and Nain (2013) reported a relatively higher use of outpatient services by women $[11,17]$. Yet, the studies by Dunlop (2000) and Miltiades (2008) found that men use more outpatient services $[10,22]$. It seems that the higher rate of utilization of health services by women is due to their higher sensitivity and attention to the health issues and preventive measures. Although household income was reported in some studies to have a positive effect on the utilization of health services [3, $9,11,12,15,23,24]$, it was reported to have a negative effect in one study [25]. The study by Lee et al. (2011) indicated that the low-income people used more health services when they were covered by a type of health insurance. Moreover, some studies reported that those households that had high expenditures also had a high rate of utilizing inpatient services [21, 26]. However, the study by Nooraiee Motlagh et al. (2014) showed that those families who had high expenditures, such as a rented house, had a low rate of utilizing inpatient services [27]. It seems that it depends on other factors such as out-of-pocket payment and the insurance coverage. The nature of the household expenditure as an indicator is that the high expenditure in some cases means a high income; but in other cases, it may mean the low ability of the families to spend on health services, especially when they are not covered by any type of health insurance or the out-of-pocket payment is high. There was also a conflict regarding the role of smoking and alcohol consumption. Although the study by Dunlop et al. found smoking and alcohol to have a positive effect on utilizing outpatient services [12], Gong et al. reported that less smoking and alcohol consumption results in a higher use of inpatient and outpatient services [21]. This might be due to an incorrect identification of smokers and alcoholics in 
the conducted studies or the assumption that those people who had risky behaviors in the past had started to care more about their health. As smoking and alcohol are risk factors for many noncommunicable diseases, it can be assumed that many consumers have cardiovascular diseases, blood pressure, or other related diseases that oblige them to use more health services. Another possible reason might be that the smokers and alcoholics, due to concerns about their health, use more physician visits, screening, and diagnostic services. Regarding the people with chronic diseases, there was a unanimous agreement between almost all studies that these people had reported to have a higher utilization of all categories of health services $[12,16,18,19$, $20,22,25,26,28,29]$. This is probably due to their higher need for health services. As expected, the health insurance coverage and having private health insurance were reported to have a positive effect on the utilization of health services $[15,17,21,23,24,30]$. As health insurance provides better financial access to health services, those covered by a type of health insurance tend to use health services more than uninsured ones. The main limitation of this study was that it merely included the studies published in Persian and
English. There might be some studies in other languages that would add to the findings of the study. However, the authors of this study used English as it is the formal language of most international scientific journals and Persian as it is the formal language of Iran.

\section{Conclusion}

This study systematically reviewed the literature on utilization of pharmaceutical, diagnostic, inpatient, and outpatient health services. The identified factors that affect the utilization of health services were categorized as demographic, socioeconomic, health services-related, health status-related, and health insurance-related factors. Identifying the effective factors of utilizing health services can, first, depict the health needs of the population, and then, help the policy makers decide the best options to satisfy the needs. Such results can also help the policy makers in rational and evidence-informed decision making on planning the health services provision.

\section{Conflict of Interest}

None declared.

References

1. Hasanipour H. Why the health system in Iran is lower than 98 countries around the world 2010.

2. Baker JB, Liu L. The determinants of primary health care utilization: a comparison of three rural clinics in Southern Honduras. GeoJournal. 2006;66(4):295-310.

3. Gholami M, Nasiripoor AA, Maleki MR. The Relation Between Social Determinant of Health with Access to Health Services in Gonbad kavoos. Community Health. 2016;3(1):54-65.

4. Allin S. Equity in the use of health services in Canada and its provinces. London School of Economics and Political science; 2006.

5. Pourreza A, Nemati R. Health Economics and Elderly. Salmand Iran J Ageing. 2006;1(2):80-7.

6. Grøholt EK, Stigum H, Nordhagen R, Köhler L. Health service utilization in the
Nordic countries in 1996: Influence of socioeconomic factors among children with and without chronic health conditions. Eur J Public Health. 2003;13(1):30-7.

7. Lurie N, Slater J, McGovern P, Ekstrum J, Quam L, Margolis K. Preventive Care for Women--Does the Sex of the Physician Matter? N Engl J Med. 1993;329(7):478-82.

8. Obrist B, Iteba N, Lengeler C, Makemba A, Mshana C, Nathan R, et al. Access to health care in contexts of livelihood insecurity: a framework for analysis and action. PLoS Med. 2007;4(10):e308.

9. Almeida C, Travassos C, Porto S, Labra ME. Health sector reform in Brazil: a case study of inequity. Int J Health Serv.. 2000;30(1):129-62.

10. Dunlop S, Coyte PC, McIsaac W. Socioeconomic status and the utilisation of physicians' services: results from the 
Canadian National Population Health Survey. Soc Sci Med.. 2000;51(1):123-33.

11. T.Shaikh B, J H. Health seeking behaviour and health service utilization in Pakistan: challenging the policy makers. J Public Health (Oxf).27(1):49-54.

12. Andersen R, Newman JF. Societal and individual determinants of medical care utilization in the United States. Milbank Mem Fund Q Health Soc. 2005;83(4):Onlineonly-Online-only.

13. Shin H, Song H, Kim J, Probst JC. Insurance, acculturation, and health service utilization among Korean-Americans. J Immigr Health. 2005;7(2):65-74.

14. 2009 I-UoB. strobe-statement. 2007. https://www.strobe-statement.org/index. php?id=available-checklists.

15. Morris S, Sutton M, Gravelle H. Inequity and inequality in the use of health care in England: an empirical investigation. Soc Sci Med. 2005;60(6):1251-66.

16. EbadiFardAzar F, Rezapour A, Abbasi Broujeni F, safari H, Moeeni Naeeni M. Utilization of health care services in the state of Isfahan. Hospital Journal. 2011;10(38).

17. Nain C, Kai YC, Yi CH, Yee NS, Yi LM, Jun LX et al. Knowledge of medication use and factors influencing the utilisation of public health clinics. Int Health. 2013;5(3):217-22.

18. Pappa E, Kontodimopoulos N, Papadopoulos AA, Tountas Y, Niakas D. Prescribed-drug utilization and polypharmacy in a general population in Greece: Association with sociodemographic, health needs, healthservices utilization, and lifestyle factors. Eur J Clin Pharmacol. 2011;67(2):185-92.

19. Sistrom C, McKay NL, Weilburg JB, Atlas SJ, Ferris TG. Determinants of diagnostic imaging utilization in primary care. Am J Manag Care. 2012;18(4):e135-e44.

20. Borhaninejad V, NaghibzadehTahami A, Nabavi H, Rashedi V, Yazdi-Feyzabadi $\mathrm{V}$. The utilization of health services and its influences among elderly people in Kerman-2014. Journal of North Khorasan University of Medical Sciences. 2015;7(2):229-40.

21. Gong CH, Kendig H, He X. Factors predicting health services use among older people in China: An analysis of the China Health and Retirement Longitudinal Study 2013. BMC Health Serv Res. 2016;16(1).
22. Miltiades HB, Wu B. Factors affecting physician visits in Chinese and Chinese immigrant samples. Soc Sci Med. 2008;66(3):704-14.

23. Abenhaim HA, Azziz R, Hu J, Bartolucci A, Tulandi T. Socioeconomic and Racial Predictors of Undergoing Laparoscopic Hysterectomy for Selected Benign Diseases: Analysis of 341487 Hysterectomies. J Minim Invasive Gynecol. 2008;15(1):11-5.

24. Cifaldi M. Factors affecting health services utilization in the medicare population: Would providing prescription drug coverage to medicare recipients affect their use of health care resources? Research in Human Capital and Development2001. p. 119-41.

25. Lee FH, Li CY, Wang HH, Yang YM. The utilization of Pap tests among different female medical personnel: A nationwide study in Taiwan. Prev Med. 2013;56(6):4069 .

26. Tian WH, Chen CS, Liu TC. The demand for preventive care services and its relationship with inpatient services. Health Policy. 2010;94(2):164-74.

27. Nooraiee Motlagh S, Saber Mahani A, Barooni M, Vaez Mahdavi M, Hadian M. Determining factors related to health services utilization: case of Tehran. Razi Journal of Medical Sciences. 2014-2015;21(127).

28. Lee FH, Wang HH. The utilization of pap test services of women: A nationwide study in Taiwan. Cancer Nurs. 2011;34(6):464-9.

29. Siti Fatimah AG, Aniza I, Shamsuddin K, Zailiza S. Remeasurement, evaluation and comparison the health services utilization among women staff at universiti kebangsaaan malaysia after eleven years period (20012012). Malays J Public Health Med. 2013;13(2).

30. Ohta B, Kronenfeld JJ. Intensity of acute care services at the end of life: Nonclinical determinants of treatment variation in an older adult population. J Palliat Med . 2011;14(6):722-8. 